\title{
Comparing King, Gentoo, and Royal Penguin Responses to Pedestrian Visitation
}

\author{
NICK D. HOLMES, ${ }^{1,2}$ School of Geography and Environmental Studies, University of Tasmania, Private Bag 78, Hobart, Tasmania 7001, Australia, \\ and Human Impacts Researcb Programme, Australian Antarctic Division, Channel Higbway, Kingston, Tasmania 7050, Australia.
}

\begin{abstract}
For wildlife managers, determining inter-species differences in the behavioral responses of seabirds to visitation can allow greater efficacy of visitor guidelines. Two key management outcomes for such information include 1) tailoring visitor guidelines to protect the most sensitive species and 2) improving self-regulation during visits by identifying behaviors likely to indicate a change in the natural activity of visited species. On subantarctic Macquarie Island, Australia, I collected the behavioral responses of guarding king (Aptenodytes patagonicus), gentoo (Pygoscelis papua), and royal (Eudyptes schlegeli) penguins before, during, and after exposure to a standardized pedestrian visit, to compare species' behavioral responses to visitation. Gentoo penguins appeared more sensitive than royal or king penguins, exhibiting altered behavior for 5 minutes after the stimulus was removed; this pattern was not evident in kings or royals. Response behaviors useful for visitors to assess their impact on penguins include vigilance (repeated rapid head turning) in all 3 species, agonism in king and royal penguins (reaching and striking at conspecifics), and low threat-display (bill pointing) in gentoo penguins. This study is valuable for wildlife managers as it provides practical information in the application of on-ground visitor guidelines. (JOURNAL OF WILDLIFE MANAGEMENT 71(8):2575-2582; 2007)
\end{abstract}

\section{DOI: $10.2193 / 2005-715$}

KEY WORDS behavior, gentoo, human disturbance, king, penguin, royal, subantarctic, visitor management.

Open-nesting, colonial seabirds often experience temporal and spatial overlap with human activities, and breeding sites are typically assigned high conservation value to ensure breeding can occur undisturbed (Yorio and Boersma 1992, Giese 1999, Yorio et al. 1999). Pedestrian visitation is a common form of human activity that many breeding seabirds are exposed to (Burger and Gochfield 1993, Giese 1999, Yorio et al. 2001) and this is variously managed through management zoning to spatially exclude visitors (Tasmanian Parks and Wildlife Service [TPAWS] 2003a), infrastructure to direct or exclude human movement (e.g., fences, boardwalks; Ikuta and Blumstein 2003, Beale and Monaghan 2004a), or generic guidelines for visitors to selfregulate their activity (e.g., Stokes et al. 1996, Claridge 1997, Rodgers and Smith 1997, Giese 1998). At locations where $\geq 1$ seabird species breeds, including mixed-species assemblages, visitor guidelines are typically applied to all species (Umweltbundesant 2002, International Association of Antarctica Tour Operators [IAATO] 2003, TPAWS $2003 b$ ). However, responses to visitation will vary between species (Fernández-Juricic et al. 2002, 2004; Blumstein et al. 2003, 2005), suggesting that optimal management of such visitation should consider species-specific responses.

Implicit in many visitor guidelines is the expectation that visitors will accurately assess their own impact, based on the observed responses of the birds, and will either withdraw from their activity or put greater distance between themselves and the breeding birds if signs of disturbance or modified behavior are evident (Claridge 1997, Umweltbundesant 2002, IAATO 2003, TPAWS 2003b, Australian Antarctic Division [AAD] 2004). However, explanations of

${ }^{1}$ E-mail: ndholmes@utas.edu.au

${ }^{2}$ Present address: Kauai Endangered Seabird Recovery Project, P.O. Box 458, Waimea, HI 96796, USA how to identify modified behavior, or how this may vary between species, are rarely given.

Many penguin species are colonial breeders, occupying open, accessible nest sites in locations that are regularly exposed to human visits (Naveen 2003, McClung et al. 2004, Holmes et al. 2005, Walker et al. 2005). Colonies are often situated in remote locations, and managers rely on guidelines or codes of conduct for self-regulated visits to minimize any potentially harmful effects of visitation on the birds (Antarctica New Zealand 2000, AAD 2002, Umweltbundesant 2002, IAATO 2003). Gentoo (Pygoscelis papua), king (Aptenodytes patagonicus), and royal (Eudyptes scblegeli) penguins represent 3 of the 4 breeding species of penguin on Macquarie Island $\left(54^{\circ} 30^{\prime} \mathrm{S}\right.$ $158^{\circ} 57^{\prime} \mathrm{E}$ ), with the latter being endemic. All 3 species breed along beaches and coastal slopes and are exposed to pedestrian activity from 2 main sources: government management programs (including the Australian Antarctic Program [AAP] and the Tasmanian Parks and Wildlife Service) and commercial tourism. Although management guidelines exist to control human activity around the birds (including spatial zoning and a 5-m minimum approach distance [TPAWS $2003 a, b]$ ), there has been limited scientific validation of guidelines (Holmes et al. 2005, 2006), and the same controls are applied irrespective of species. Reviewing the guidelines for people visiting wildlife on Macquarie Island is cited as a research and management priority (TPAWS 2003a).

The aims of this study were to compare the responses of guard-phase king, gentoo, and royal penguins breeding at Macquarie Island, Australia, to a standard pedestrian approach stimulus to 1) identify what behaviors characterize each species' response and 2) consider which species may be more sensitive to visitation.

\section{STUDY AREA}

Sub-Antarctic Macquarie Island is a World Heritage Area, a United Nations Educational, Scientific and Cultural 


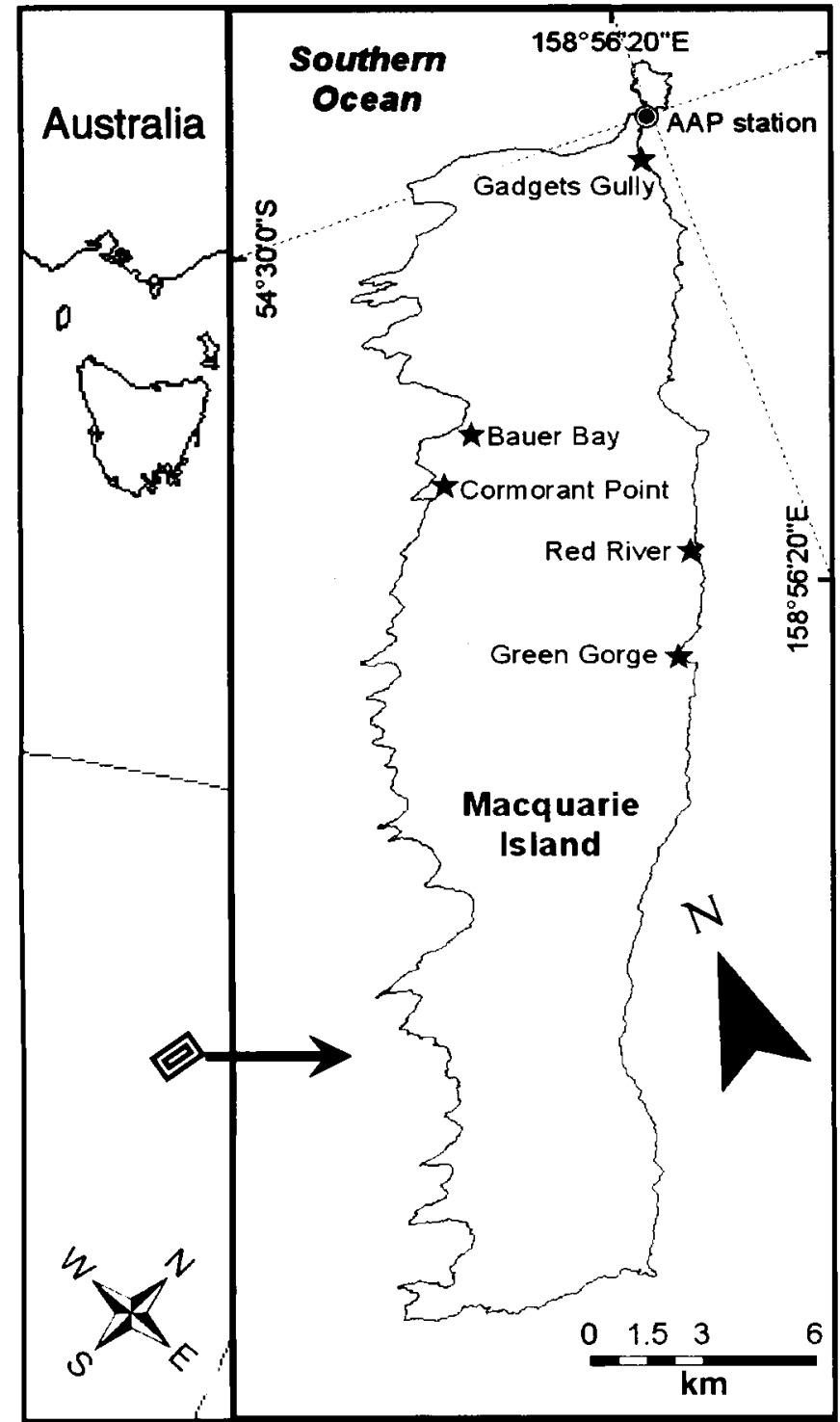

Figure 1. Location of king, royal, and gentoo study colonies on Macquarie Island, Australia, 2001-2003.

Organization (UNESCO) Biosphere Reserve, and a Tasmanian Nature Reserve (TPAWS 2003a). Management of activities falls under the Tasmanian Parks and Wildlife Service, the Tasmanian Department of Primary Industries, Water and Environment, and the Australian Antarctic Division. As part of the government programs, between 10 and 40 people occupy the island year round, with higher numbers present from October to March, corresponding with the summer science program. In addition, between 2 and 8 tourist vessels currently visit Macquarie island per season, with 40-100 people arriving ashore per trip, and typically $<20$ total visitor-days per summer (TPAWS 2003a).

Royal penguins were sampled from 4 colonies between Green Gorge and Red River (Fig. 1) each containing $\leq 10,000$ breeding pairs (Schulz and Lynn 2004). I sampled king penguins from 2 colonies at Green Gorge and Gadgets Gully (Fig. 1), which contained approximately 550 and 90 breeding pairs, respectively. I sampled gentoo penguins from 2 colonies at Bauer Bay and Cormorant Point, which contained 155 and 122 breeding pairs, respectively (N. D. Holmes, University of Tasmania, unpublished data; Fig. 1). Macquarie Island has a mean summer temperature range of $3.3-7.0^{\circ} \mathrm{C}$ and a mean precipitation of $920 \mathrm{~mm}$ over 312 days (TPAWS 2003a). All colonies were situated between tall tussock grassland (Poa foliosa) and pebbled beaches on low open slopes or flat land (Selkirk et al. 1989). To reduce likelihood of prior exposure to human activity influencing results (Holmes et al. 2006), minimal human visitation occurred to sampled colonies outside of controlled experiments.

\section{METHODS}

Ethics approval was granted from the Australian Antarctic Animal Ethics Committee (project 1148) and the University of Tasmania Animal Ethics Committee (Approval No. A0006949). Macquarie Island access permits were issued by the Tasmanian Parks and Wildlife Service, and scientific permits were issued by the Nature Conservation Branch of the Tasmanian Department of Primary Industries, Water and Environment (Permit No. MI 02188).

Field work occurred from 1 December to 10 December 2001 (royals, $n=24$ ), 26 October to 4 November 2002 (gentoos, $n=26$ ) and 4 March to 13 March 2003 (kings, $n=$ 26). These periods encompassed guard phase for each species, when chicks were nest-bound and approximately $<3$ weeks of age (Williams 1995).

Experiments followed a before (preapproach), during (approach), and after (postapproach) design (Holmes et al. 2005,2006 ), with 20 minutes of behavior recorded prior to human approaches (i.e., preapproach) and 15 minutes following approaches (i.e., postapproach). No humans were visible to focal penguins during pre- and postapproach periods. The standardized pedestrian stimulus (approach), consisted of a single person walking to $5 \mathrm{~m}$ from focal birds (following the current Tasmanian Parks and Wildlife Service min. approach distance guideline [TPAWS 2003b]) at $1 \mathrm{~m}$ per second, standing for 60 seconds, crouching for 60 seconds, then retreating along original route, lasting $\leq 5$ minutes. All approaches were done by the same person wearing a red jacket, who remained still and quiet in front of penguins.

Penguin behavior was recorded on a $\mathrm{Hi}-8$ video camera (Sony TRV, Taiwan) from a remote observation post. I selected only edge-nesting penguins for experiments, as these individuals were exposed to the greatest potential disturbance from pedestrians and also controlled for the influence of nest location within the colony (Tenaza 1971). Nesting density is typically constant at king and royal penguin colonies (Willams 1995). Nest density at gentoo colonies on Macquarie Island can vary, so to provide consistency we sampled edge-nesting birds where distance to nearest neighbor showed least variation $( \pm 0.5 \mathrm{~m})$. I selected only single guarding birds (i.e., no partner was present) to eliminate the possibility of partners influencing 
Table 1. Behavior of king, gentoo, and royal penguins quantified before, during, and after exposure to single-person pedestrian approach, Macquarie Island, Australia, 2001-2003.

\begin{tabular}{|c|c|}
\hline Behavior & Description \\
\hline \multicolumn{2}{|l|}{ State $^{2}$} \\
\hline Rest & Motionless, sleeping, or undertaking comfort events. \\
\hline Self-maintenance & $\begin{array}{l}\text { All related nest- or body-maintenance activities, including preening and nesting (e.g., gathering rocks for the nest; } \\
\text { Stonehouse } 1960 \text {, Smith } 1970 \text {, van Zindren Bakker 1971). }\end{array}$ \\
\hline Chick-maintenance & Interacting with chick, including preening and feeding (Stonehouse 1960, Smith 1970, van Zindren Bakker 1971). \\
\hline Threat-display & $\begin{array}{l}\text { Bowing to head-swinging in royals; bowing, ecstatic display, and horizontal head circling in kings; low to high } \\
\text { display and low threat to tete-à-tete in gentoos (Stonehouse 1960; van Zindren Bakker 1971; Warham 1971, } \\
\text { 1975; Jouventin 1982). }\end{array}$ \\
\hline \multicolumn{2}{|r|}{1775 , Jouverilu 1702). } \\
\hline Vigilance & $\begin{array}{l}\text { A single vigilance event was scored as turning the head from } 0^{\circ} \text { to } 180^{\circ} \text { from a facing-forward position, or } \\
\text { extending the neck. }\end{array}$ \\
\hline Agonism & Reaching or striking at offender (e.g., conspecific; Smith 1970, Warham 1975). \\
\hline Swallowing & Typically following bill-shaking (Ainley 1974, Jouventin 1982), as described in Holmes et al. (2005). \\
\hline Comfort & $\begin{array}{l}\text { Yawning, defecating, tail-wagging, body shakes, jaw stretches, and full body stretches (Stonehouse 1960; } \\
\text { Smith 1970; van Zindren Bakker 1971; Warham 1971, 1975). }\end{array}$ \\
\hline Movement & Walking or other locomotor events taking birds away from stationary position. \\
\hline
\end{tabular}

"State behaviors measured as \% time spent.

${ }^{b}$ Event behaviors measured as frequency of acts $/ \mathrm{min}$.

the responses of focal birds. When a partner returned to the nest during an experiment, I discontinued the experiment and analyzed only the behavior I recorded up to 2 minutes prior to the first sign of courtship activity between the pair (following Stonehouse 1960, Smith 1970, van Zindren Bakker 1971, Warham 1975). I only conducted experiments during specific weather windows, whereby wind $<25$ knots measured at $2 \mathrm{~m}$ above ground level using a Speedtech Instruments Weathermate (Speedtech Instruments, Great Falls, VA) and there was light or no precipitation, based on Australian Bureau of Meteorology definitions (Bureau of Meteorology 2001).

\section{Behavior}

I classified behaviors as either states or events (after Altman 1974), and we thus measured them as a percentage of observed time or the frequency of occurrence per minute, respectively. I used the software The Observer 5.0 (Noldus Information Technology 2002) for all behavioral analyses.

I analyzed 9 behaviors, common to all species, including rest, self-maintenance, chick-maintenance, vigilance, agonism, comfort, swallowing, threat-display, and movement (Table 1). For gentoo penguins, I combined threat and display behaviors, because low threat behavior and low display behavior (following van Zindren Bakker 1971) were often indistinguishable. Threat and display behaviors in royal penguins and agonistic behaviors in gentoo penguins occurred too rarely for analyses, so I removed them from the data set. Bill-shaking has been previously identified as a displacement behavior in penguins (Jouventin 1982); however, I chose swallowing as a surrogate for bill-shaking as swallowing typically follows bill-shaking in royal penguins (Holmes et al. 2005). I monitored movement (from position at start of exp.) for all focal penguins.

\section{Statistical Analyses}

I conducted analyses in 2 stages. The first stage investigated responses to approaches for each species separately to characterize the behavioral response of king, gentoo, and royal penguins. Prior to analyses, I split preapproach recordings into 45 -minute periods and calculated the mean. I split postapproach recordings into 3 consecutive 5minute segments to determine if and when behavior returned to preapproach levels. I subsequently compared approach and postapproach behaviors to preapproach levels using a series of paired $t$-tests (paired differences), following Zar (1996).

The second stage of analysis compared the difference between species. This involved comparing the paired differences from the first analysis stage (approach and postapproach vs. preapproach periods) across species, rather than comparing the absolute response of each species, using Welch's $F$-tests (analysis of variance [ANOVA] for groups with unequal variances) and Games-Howell post hoc tests.

Where necessary, I arcsine-transformed percentage data or continuous data $\log (x+1)$ prior to testing to meet assumptions of normality (Zar 1996). Where the paired differences did not conform to the assumption of normality (e.g., for movement, agonism, comfort), sample sizes and the nature of the data would ensure the tests were robust against these deviations. I used a conservative measure of $P$ $<0.01$. I used SPSS Version 12 (Chicago, IL) for statistical analyses of behaviors.

\section{RESULTS}

\section{Behavior in the Absence of Human Activity}

Behavior during the preapproach periods varied between species (Table 2). Royal penguins spent the highest mean percentage of time resting $(77.58 \pm 10.78 \% \mathrm{SD})$, whereas king penguins spent the highest mean percentage of time performing self-maintenance activities (17.31 $\pm 10.82 \%$ $\mathrm{SD})$ and were the most aggressive, performing $1.76 \pm 0.74$ (SD) agonistic acts per minute. Gentoo penguins were the most vigilant, performing $12.59 \pm 9.85$ (SD) vigilant acts 
Table 2. Behavior of king $(n=26)$, gentoo $(n=24)$, and royal $(n=26)$ penguins in the absence of human activity (preapproach), Macquarie Island, Australia, 2001-2003. Values are means and standard deviations derived from raw data.

\begin{tabular}{|c|c|c|c|c|c|c|}
\hline \multirow[b]{2}{*}{ Behavior } & \multicolumn{2}{|c|}{ King } & \multicolumn{2}{|c|}{ Royal } & \multicolumn{2}{|c|}{ Gentoo } \\
\hline & $\tilde{\boldsymbol{x}}$ & SD & $\overline{\boldsymbol{x}}$ & SD & $\tilde{\boldsymbol{x}}$ & SD \\
\hline \multicolumn{7}{|l|}{ State $^{2}$} \\
\hline Rest & 30.49 & 18.23 & 77.58 & 10.78 & 39.37 & 30.53 \\
\hline Chick-maintenance & 5.93 & 6.04 & 6.81 & 4.90 & 5.08 & 6.77 \\
\hline Self-maintenance & 17.31 & 10.82 & 10.96 & 7.34 & 10.31 & 8.83 \\
\hline Threat-display & 11.89 & 6.43 & & & 2.25 & 3.66 \\
\hline \multicolumn{7}{|l|}{ Event $^{b}$} \\
\hline Comfort & 0.08 & 0.07 & 0.14 & 0.13 & 0.04 & 0.09 \\
\hline Swallow & 0.23 & 0.22 & 0.19 & 0.14 & 0.47 & 0.48 \\
\hline Agonism & 1.76 & 0.74 & 0.08 & 0.07 & & \\
\hline Vigilance & 2.05 & 0.81 & 1.05 & 0.39 & 12.59 & 9.85 \\
\hline
\end{tabular}

State behaviors measured as \% time spent.

bvent behaviors measured as frequency of acts/min

per minute. All species spent $5-7 \%$ of their time undertaking chick-maintenance.

\section{Species Responses to Pedestrian Approaches}

During approaches to king penguins, one individual temporarily abandoned its chick at the smaller colony sampled ( 90 breeding pairs), moving $\geq 5 \mathrm{~m}$ away before reuniting with the chick 25 seconds later. This occurred as the person approached from $30 \mathrm{~m}$ to $5 \mathrm{~m}$ and concurrently several conspecifics moved in amongst breeding birds. I removed this individual from the data set for analysis purposes. During approaches, king penguins displayed increased vigilance $\left(t_{23}=6.00, P<0.001\right)$ and agonistic activity $\left(t_{23}=3.98, P=0.001\right)$, relative to preapproach levels. No other significant change in king penguin behavior was recorded during or after $(0-15 \mathrm{~min})$ the approach $(P>$ 0.01; Fig. 2).

When approached, royal penguins displayed higher levels of vigilance $\left(t_{23}=13.73, P<0.001\right)$, agonistic activity $\left(t_{23}=\right.$ 3.56, $P=0.002)$, and lower resting levels $\left(t_{23}=-9.07, P<\right.$ 0.001 ), relative to preapproach levels. Following the approach, all royal penguin behaviors were comparable to preapproach levels for the remainder of the experiment (0-15 $\min , P>0.01)$. No changes were recorded in movement, chick-maintenance, self-maintenance, or swallowing behaviors of royal penguins for the entire experiment $(P>0.01$; Fig. 2).

During the approach, gentoo penguin responses were characterized by increases in vigilance $\left(t_{25}=7.55, P<\right.$ $0.001)$ and threat-display behavior $\left(t_{25}=3.86, P=0.001\right)$ and by lower resting levels, relative to preapproach $\left(t_{25}=\right.$ $-5.42, P<0.001)$. Of the threat behaviors displayed during the approach, $92 \%$ consisted of low threat-display. For 0-5 minutes following the approach, vigilance remained higher than preapproach levels $\left(t_{25}=2.94, P=0.007\right)$, and for $5-10$ minutes following the approach greater time was spent performing self-maintenance $\left(t_{24}=2.75, P=0.01\right)$. No changes were recorded in movement, chick-maintenance, swallowing or comfort activities, relative to preapproach levels $(P>0.01$; Fig. 2).

\section{Comparing Species Responses}

During the approach, the extent to which each species displayed chick-maintenance, swallowing, movement and comfort behaviors were not different $(P>0.01)$. However, there was evidence that rest behavior was more interrupted during approaches to gentoo and royal penguins than it was for king penguins $\left(F_{2,46.7}=10.93, P<0.001\right)$. The increased levels of vigilance, relative to preapproach, were comparable between species $\left(F_{2,45.6}=1.16, P=0.324\right)$. There was no difference in the extent to which agonistic activity increased during approaches for king and royal penguins $\left(F_{2,46.1}=3.59, P=0.36\right)$ but the increased levels of threat-display behavior recorded in gentoos was higher than that recorded in kings $\left(F_{2,45.0}=8.52, P=0.005\right.$; Fig. 2$)$.

Following the approach, the increased vigilance recorded in gentoos was higher than for kings or royals $\left(F_{2,44.8}=\right.$ 4.98, $P=0.010)$. The increased self-maintenance activity recorded 5-10 minutes following the approach in gentoos overlapped with the variation in king and royal selfmaintenance activity, and the difference between species was, thus, not statistically significant $\left(F_{2,40.4}=4.42, P=\right.$ 0.018 ; Fig. 2). No other significant difference in behavioral responses was recorded between species following the approach (0-15 $\mathrm{min}, P>0.01)$

\section{DISCUSSION}

\section{Behavior in the Absence of Human Activity}

The 3 species studied belong to 3 different families of the order sphenisciformes. Penguin breeding behavior varies on a family level, reflecting the evolutionary adaptation of each species to successfully rear offspring (Jouventin 1982). For royal penguins, the behavior reported here is within the observed variation recorded from other studies of this and closely related species (Smith 1970, 1974; Haftorn 1986), and this account of king and gentoo penguin behavior is consistent with other published ethological descriptions for these species (Stonehouse 1960, van Zindren Bakker 1971). Although these results should not be considered a complete quantification of the guard-phase behavior of king, royal, 

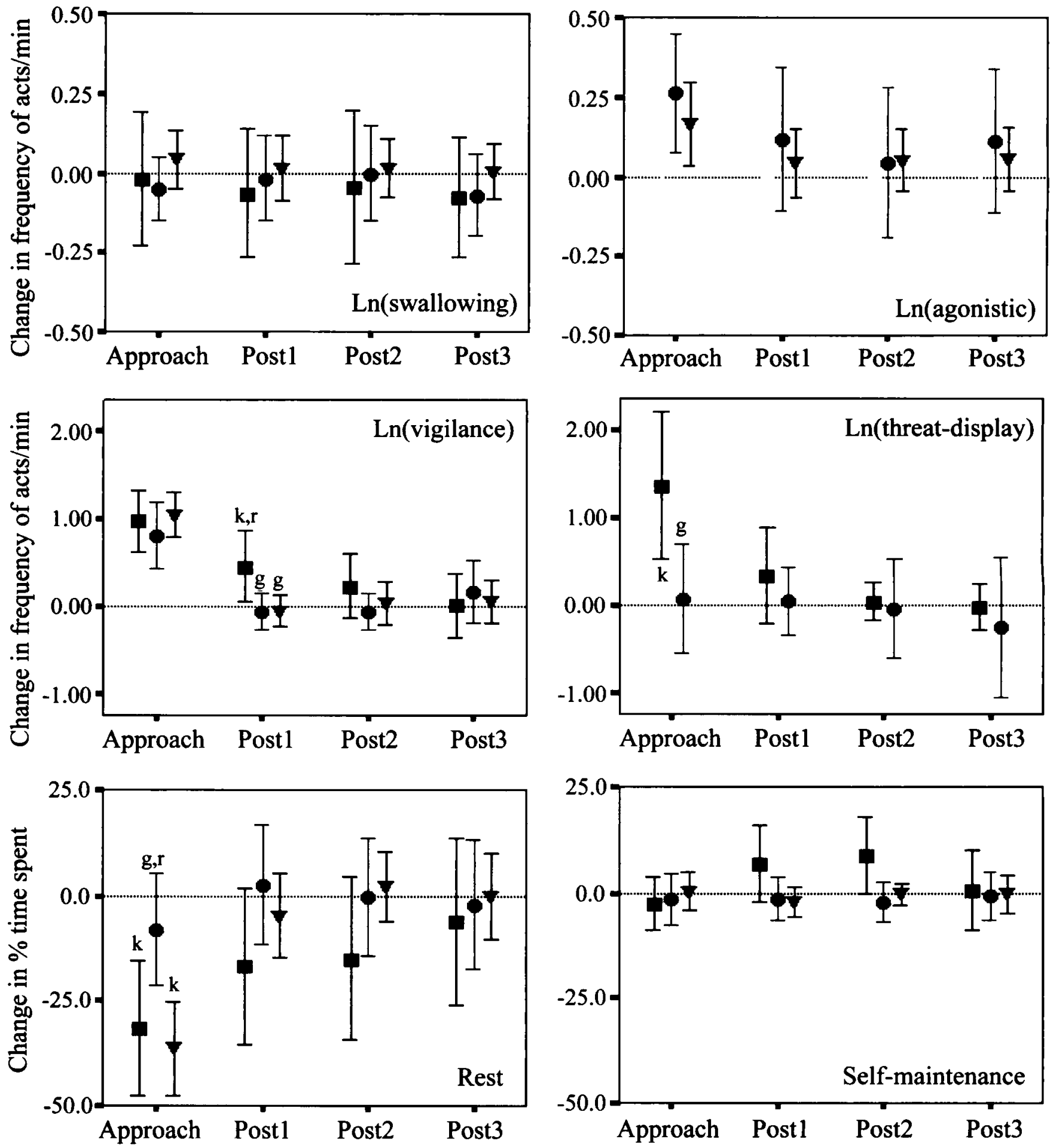

Figure 2. Change in behavior of king (circles, $n=26$ ), gentoo (squares, $n=26$ ), and royal (triangles, $n=24$ ) penguins during and after single person approach, Macquarie Island, Australia, 2001-2003. Changes are expressed as the difference between approach or postapproach values versus preapproach values. Error bars are $99 \%$ confidence intervals, and when not crossing zero (dashed lines) indicate a significant difference between approach or postapproach and preapproach values $(P<0.01)$. Significant differences between species $(P<0.01)$ are indicated by first letters of each species' common name.

and gentoo penguins, they provide baseline values of undisturbed behavior for the purpose of this study.

\section{Which Species is More Sensitive to Visitation?}

Amongst seabirds and waterbirds, responses to human activity have been demonstrated to vary due to a number of factors other than species type, such as frequency of visitation and habituation (Dunlop 1996; Holmes et al. 2005; Walker et al. 2005, 2006), stimulus type (Rodgers and Smith 1995, 1997), breeding density (Hockey and Hallinan 1981), stage of breeding (Götmark 1992, Yorio and Quintana 1996, Bolduc and Guillemette 2003), individual variation (de Villiers et al. 2005), and food availability (Beale 
and Monaghan 2004b). With the exception of food availability, I controlled these factors as much as possible; however, they may still account for some unexplained variation.

The risk-disturbance hypothesis provides a valuable context to understanding wildlife responses to human activity (Frid and Dill 2002), whereby wildlife may perceive anthropogenic sources of interaction as they would the risk of predation, ultimately balancing predation risk (mortality) against survivorship (Frid and Dill 2002, Beale and Monaghan 2004a, Blumstein et al. 2005). During this study, the behavioral responses of decreased rest and increased vigilance, agonism and threat-display during approaches fit within this theoretical framework, suggesting that a single person approaching breeding penguins can be perceived as a predation risk. Consequently, these behavioral responses may represent a precursor to a fight-or-flight response, as observed in other seabirds (Ball and Amlaner, Jr. 1980; Giese 1998; de Villiers et al. 2005; Holmes et al. 2005, 2006).

Each species examined here demonstrated a different behavioral pattern in response to the same pedestrian stimulus. However, gentoo penguins demonstrated significantly increased levels of vigilance for 5 minutes and significantly increased self-maintenance for 5-10 minutes following approaches, a pattern not evident in kings or royals, suggesting that gentoos are more sensitive to a single person visiting the nest than the other 2 species. Gentoo penguins have been commonly referred to as shy near human activity at a number of locations (van Zinderen Bakker 1971, Williams 1980, Reilly and Kerle 1981, Bost and Jouventin 1990). On Marion Island ( $46^{\circ} 54^{\prime} \mathrm{S} 37^{\circ} 05^{\prime} \mathrm{E}$ ), this sensitivity is reflected in management guidelines, where the recommended minimum approach distance to king, macaroni ( $E$. chrysolophus), and rockhopper (E. chrysocome) penguins is $15 \mathrm{~m}$; however, an exclusion zone of $100 \mathrm{~m}$ exists around all gentoo penguin colonies (Prince Edward Islands Management Plan Working Group 1996).

Gentoos are not regarded as sensitive to human activity at all breeding locations. Studies on the Antarctic Peninsula suggest that regular tourism does not impact gentoo penguins there (Nimon et al. 1995, Cobley and Shears 1999, Cobley et al. 2000), and the recommended minimum approach distance for breeding penguins is $4.5 \mathrm{~m}$ (IAATO 2003). Although it is unclear if gentoos at some locations on the Antarctic Peninsula may have habituated to regular tourism, gentoos on Macquarie Island that were exposed to regular human activity demonstrated reduced sensitivity to human presence, suggesting habituation can occur (Holmes et al. 2006). All penguins that I studied bred away from regular human activity and were subsequently considered naive to the stimulus presented. The increased agonistic activity by kings, appeared to be an indirect consequence of the approaches, whereby the pedestrian instigated the sudden movement of molting, loafing, or resting birds into or alongside breeding animals. Consequently, the responses we observed may not necessarily represent an increased threat due to the pedestrian visit but rather due to crowding by conspecifics. The unique breeding schedule of king penguins, whereby individuals typically breed twice every 3 years, produces asynchrony in the initiation of breeding tasks, and breeding birds will commonly be surrounded by conspecifics engaged in other tasks such as molting and courtship (Stonehouse 1960).

The breeding king that temporarily abandoned its chick during the approach most likely did so because of interference from sudden movement of conspecifics. This may have been an artifact of the smaller colony size where this occurred, individual variation, or some other unidentified factor. Regardless, a precautionary perspective would suggest that a king penguin may occasionally temporarily abandon its chick when approached, an undesirable management outcome as this increases the risk of mortality through predation or aggressive interactions with other breeding adults (Claridge 1997).

\section{What Penguin Behaviors Indicate a Response to Visitation?}

For people visiting breeding kings, gentoos, and royals, identifying altered penguin behavior has some inherent impracticalities. For example, it would be impossible for visitors to identify decreased rest in an animal without some assessment of this behavior prior to visitation. During this study, no behavior could be reliably regarded as an exclusive response to pedestrian presence. However, certain behaviors appear likely to prove useful as indicators of modified penguin behavior in response to human activity.

Change in vigilance (common to all species) can be easily identified when it develops into rapid turning of the head accompanied by stretched, vertical extensions of the neck. Increased agonistic behavior (reaching or striking) in response to increased movement of nonbreeding penguins within the colony is also relatively easy to identify. Increased alert and agonistic behaviors in response to pedestrian approaches have also been recorded in African (Spheniscus demersus; van Heezik and Seddon 1990) and Adélie penguins ( $P$. adeliae; Giese 1998), suggesting that these behaviors are a common response among a broader range of penguin species.

For gentoo penguins, facets of ritualized low threatdisplay behavior, particularly vertical bill pointing, would prove useful as a behavioral indicator given it constituted a consistent part of the penguins' response to humans. Adélie penguins have also been recorded to display facets of their ritualized threat and display behaviors (e.g., sideways stares; Spurr 1975) when approached by people (Giese 1998), suggesting that such behaviors may be useful for identifying modified behavior among other pygoscelid species exposed to anthropogenic sources.

In addition to monitoring wildlife behavior, it is welldocumented that visitor behavior can also significantly influence the level of intensity of a penguin's response (Wilson et al. 1991, Giese 1998, Martin et al. 2004). I simulated a low-impact visitation to breeding penguins (no noise, no rapid movements, single person), and the 
behaviors we elicited should be considered a minimum response to visitation.

\section{MANAGEMENT IMPLICATIONS}

This study is valuable for wildlife managers as it provides practical information in the application of on-ground visitor guidelines (Blumstein 2003; Blumstein et al. 2003, 2005; Holmes et al. 2005). On Macquarie Island, promoting monitoring of penguin behaviors by visitors will make selfregulation of impact more effective. Caution is required for pedestrian activity near king penguin colonies to reduce likelihood of conspecifics crowding breeding birds. Finally, the blanket guidelines for minimizing human impact near penguin colonies currently do not appear to cater for greater gentoo penguin sensitivity. More conservative visitor guidelines would alleviate this, such as greater minimum approach distances or exclusionary zoning near colonies.

\section{ACKNOWLEDGMENTS}

Geographic data for maps were supplied by the Australian Antarctic Data Centre. We gratefully appreciate the assistance by members of the 53rd and 54th Australian National Antarctic Research Expeditions to Macquarie Island, particularly A. Dermer, B. Ries, and H. Achurch. Many thanks to M. Giese, L. K. Kriwoken, and L. Taddonio for manuscript improvements and to G. McPherson for statistical advice. This study was financially and logistically supported by an Australian Antarctic Scientific Advisory Committee grant, Birds Australia, the School of Geography and Environmental Studies University of Tasmania, the Cooperative Research Centre for Sustainable Tourism, and the Holsworth Wildlife Research Fund.

\section{LITERATURE CITED}

Ainley, D. G. 1974. The comfort behaviour of Adélie and other penguins. Behaviour 50:16-51.

Altman, J. 1974. Observational study of behaviour: sampling methods. Behaviour 49:227-265

Antarctica New Zealand. 2000. Environmental stewardship. Conservation of flora and fauna. <http://www.antarcticanz.govt.nz/Pages/ Environment/FloraFauna.msa>. Accessed 31 Mar 2004.

Australian Antarctic Division (AAD). 2002. Environmental code of conduct for Australian field activities in Antarctica. Australian Antarctic Division, Kingston, Tasmania, Australia.

Australian Antarctic Division (AAD). 2004. Minimum approach distances to wildlife in Antarctica. <http://www.aad.gov.au/default. asp?casid $=2948>$. Accessed 30 Oct 2004.

Ball, N. J., and C. J. Amlaner, Jr. 1980. Changing heart rates of herring gulls when approached by humans. Pages 589-594 in C. J. Amlaner, Jr. and D. W. McDonald, editors. A handbook on biotelemetry and radiotracking. Pergamon Press, Oxford, England.

Beale, C. M., and P. Monaghan. 2004a. Human disturbance: people as predation-free predators? Journal of Applied Ecology 41:335-343.

Beale, C. M., and P. Monaghan. 2004b. Behavioural responses to human disturbance: a matter of choice? Animal Behaviour 68:1065-1069.

Blumstein, D. T. 2003. Flight-initiation distance in birds is dependent on intruder starting distance. Journal of Wildlife Management 67:852-857.

Blumstein, D. T., L. L. Anthony, R. Harcourt, and G. Ross. 2003. Testing a key assumption in wildlife buffer zones: is flight initiation distance a species-specific trait? Biological Conservation 110:97-100.

Blumstein, D. T., E. Fernández-Juricic, P. A. Zollner, and S. C. Garity.
2005. Inter-specific variation in avian responses to human disturbance. Journal of Applied Ecology 42:943-953.

Bolduc, F., and M. Guillemette. 2003. Human disturbance and nesting success of common eiders: interaction between visitors and gulls. Biological Conservation 110:77-83.

Bost, C. A., and P. Jouventin. 1990. Evolutionary ecology of gentoo penguins (Pygoscelis papua). Pages 85-112 in L. S. Davis and J. T. Darby, editors. Penguin biology. Academic Press, San Diego, California, USA.

Bureau of Meteorology. 2001. Australian Bureau of Meteorology. Weather words. <http://www.bom.gov.au/info/wwords/>. Accessed 10 Jul 2001.

Burger, J., and M. Gochfield. 1993. Tourism and short-term behavioural responses of nesting masked, red-footed, and blue-footed, boobies in the Galápagos. Environmental Conservation 20:255-259.

Claridge, G. 1997. Guidelines for managing visitation to seabird breeding islands. Prepared by WBM Oceanics Australia for Great Barrier Reef Marine Park Authority and Environment Australia Biodiversity Group. Great Barrier Reef Marine Park Authority, Townsville, Queensland, Australia.

Cobley, N. D., and J. R. Shears. 1999. Breeding performance of gentoo penguins (Pygoscelis papua) at a colony exposed to high levels of human disturbance. Polar Biology 21:355-360.

Cobley, N. D., J. R. Shears, and R. H. Downie. 2000. The impacts of tourists on gentoo penguins at Port Lockroy, Antarctic Peninsula. Pages 319-323 in W. Davison, C. Howard-Williams, and P. Broady, editors. Antarctic ecosystems: models for wider ecological understanding. New Zealand Natural Sciences, Christchurch, New Zealand.

de Villiers, M. S., J. Cooper, and P. G. Ryan. 2005. Individual variability of behavioural responses by wandering albatrosses (Diomedea exulans) to human disturbance. Polar Biology 28:255-260.

Dunlop, J. N. 1996. Habituation to human disturbance by breeding bridled terns Sterna anaethetus. Corella 20:13-16.

Fernández-Juricic, E., M. D. Jimenez, and E. Lucas. 2002. Factors affecting intra- and inter-specific variations in the difference between alert distances and flight distances for birds in forested habitats. Canadian Journal of Zoology-Revue Canadienne De Zoologie 80:1212-1220.

Fernández-Juricic, E., R. Vaca, and N. Schroeder. 2004. Spatial and temporal responses of forest birds to human approaches in a protected area and implications for two management strategies. Biological Conservation 117:407-416.

Frid, A., and L. Dill. 2002. Human-caused disturbance stimuli as a form of predation risk. Conservation Ecology 6:11.

Giese, M. 1998. Guidelines for people approaching breeding groups of Adélie penguins (Pygoscelis adeliae). Polar Record 34:287-292.

Giese, M. 1999. Eco-tourism and seabirds: Antarctica as a case study. World Birdwatch 21:12-15.

Götmark, F. 1992. The effects of investigator disturbance on nesting birds. Pages 63-104 in D. M. Power, editor. Current ornithology. Volume 9. Plennum Press, New York, New York, USA.

Haftorn, S. 1986. A quantitative analysis of the behaviour of the chinstrap penguin Pygoscelis antarctica and macaroni penguin Eudyptes chrysolophus on Bouvetøya during the late incubation and early nestling periods. Polar Research 4:33-45.

Hockey, P. A. R., and J. Hallinan. 1981. Effect of human disturbance on the breeding behaviour of jackass penguins Spheniscus demersus. South African Journal of Wildlife Research 11:59-62.

Holmes, N. D., M. Giese, H. A. Achurch, S. A. Robinson, and L. K. Kriwoken. 2006. Behaviour and breeding success of gentoo penguins Pygoscelis papua in areas of high and low human activity. Polar Biology 29: 399-412.

Holmes, N. D., M. Giese, and L. K. Kriwoken. 2005. Testing the minimum approach distance guidelines for incubating royal penguins Eudyptes schlegeli. Biological Conservation 126:339-350.

Ikuta, L. A., and D. T. Blumstein. 2003. Do fences protect birds from human disturbance? Biological Conservation 112:447-452.

International Association of Antarctica Tour Operators (IAATO). 2003. International Association of Antarctic Tour Operators: marine wildlife watching guidelines (whales $\&$ dolphins, seals $\&$ seabirds). International Association of Antarctic Tour Operators, Basalt, Colorado, USA.

Jouventin, P. 1982. Visual and vocal signals in penguins, their evolution and adaptive characters. Supplement 24 to Journal of Comparative Ethology. Verlag Paul Parey, Berlin, Germany.

Martin, J., L. de Neve, J. A. Fargallo, V. Polo, and M. Soler. 2004. Factors 
affecting the escape behaviour of juvenile chinstrap penguins, Pygoscelis antarctica, in response to human disturbance. Polar Biology 27:775-781.

McClung, M. R., P. J. Seddon, M. Massaro, and A. N. Setiawan. 2004. Nature-based tourism impacts on yellow-eyed penguins Megadyptes antipodes: does unregulated visitor access affect fledging weight and juvenile survival? Biological Conservation 119:279-285.

Naveen, R. 2003. Compendium of Antarctic peninsula visitor sites. Second edition. A report to the United States Environmental Protection Agency. Oceanites, Chevy Chase, Maryland, USA.

Nimon, A. J., R. C. Schroter, and B. Stonehouse. 1995. Heart rate of disturbed penguins. Nature 374:415.

Noldus Information Technology. 2002. The Observer 5.0: software for collection, analysis and presentation of observational data. Noldus Information Technology, Wageningen, Gelderland, The Netherlands.

Prince Edward Islands Management Plan Working Group. 1996. Prince Edward Islands management plan. Department of Environmental Affairs and Tourism, Pretoria, Gauteng, South Africa.

Reilly, P. N., and J. A. Kerle. 1981. A study of the gentoo penguin Pygoscelis papua. Notornis 28:189-202.

Rodgers, J. A., and H. T. Smith. 1995. Set-back distances to protect nesting bird colonies from human disturbance in Florida. Conservation Biology 9:89-99.

Rodgers, J. A., and H. T. Smith. 1997. Buffer zone distances to protect foraging and loafing waterbirds from human disturbance in Florida. Wildlife Society Bulletin 25:139-145.

Schulz, M., and J. Lynn. 2004. Census of the gentoo penguin Pygoscelis papua, royal penguin Eudyptes schlegeli, imperial shag Phalacrocorax purpurascens, and the Antarctic tern Sterna vittata, Macquarie Island, October-November 2003. Tasmanian Parks and Wildlife Service, Hobart, Australia.

Selkirk, P. M., R. D. Seppelt, and D. R. Selkirk. 1989. Subantarctic Macquarie Island: environment and biology. Cambridge University Press, Cambridge, England.

Smith, G. T. 1970. Studies on the behaviour and reproduction of the royal penguin (Eudyptes chrysolophus schlegeli). Dissertation, Australian National University, Canberra, Australian Capital Territory, Australia.

Smith, G. T. 1974. An analysis of the function of some displays of the royal penguin. Emu 74:27-34.

Spurr, E. B. 1975. Communication in the Adélie penguin. Pages 499-501 in B. Stonehouse, editor. Biology of penguins. University Park Press, Baltimore, Maryland, USA.

Stokes, T., K. Hulsman, P. Ogilvie, and P. O'Neill. 1996. Management of human visitation to seabird islands of the Great Barrier Reef Marine Park. Pages 45-56 in G. J. B. Ross, K. Weaver, and J. C. Greig, editors. The status of Australia's seabirds. Biodiversity Group, Environment Australia, Canberra, Australian Capital Territory, Australia.

Stonehouse, B. 1960. The king penguin Aptnodytes patagonicus of South Georgia. I. Breeding behaviour and development. Scientific Reports of the Falklands Islands Dependency Surveys 23:1-81.

Tasmanian Parks and Wildlife Service (TPAWS). 2003a. Macquarie Island
Nature Reserve and World Heritage Area draft management plan 2003. Tasmanian Parks and Wildlife Service, Hobart, Australia.

Tasmanian Parks and Wildlife Service (TPAWS). 2003b. Parks and places. Macquarie Island World Heritage Area minimum impact code. Tasmanian Parks and Wildlife Service, Hobart, Australia.

Tenaza, R. C. 1971. Behaviour and nesting success relative to nest location in Adélie penguins Pygoscelis adeliae. Condor 73:81-92.

Umweltbundesant. 2002. Leitfaden für besucher der antarktis. Umweltbundesant, Berlin, Germany. [In German.]

van Heezik, Y., and P. J. Seddon. 1990. Effect of human disturbance on beach groups of jackass penguins. South African Journal of Wildlife Research 20:89-93.

van Zindren Bakker, E. M. J. 1971. A behavioural analysis of the gentoo penguin (Pygoscelis papua Forster). Pages 251-272 in E. M. S. van Zindren Bakker, J. M. Winterbottom, and R. A. Dyer, editors. Marion and Prince Edward Islands: a report on the South African Biological and Geological Expedition 1965-1966. A. A. Balkema, Cape Town, Western Cape, South Africa.

Walker, B. G., P. D. Boersma, and J. C. Wingfield. 2005. Physiological and behavioral differences in Magellanic Penguin chicks in undisturbed and tourist-visited locations of a colony. Conservation Biology 19:1571-1577.

Walker, B. G., P. D. Boersma, and J. C. Wingfield. 2006. Habituation of adult magellanic penguins to human visitation as expressed through behavior and corticosterone secretion. Conservation Biology 20:146-154.

Warham, J. 1971. Aspects of the breeding behaviour of the royal penguin Eudyptes chrysolophus schlegeli. Notornis 18:91-115.

Warham, J. 1975. The crested penguins. Pages 189-269 in B. Stonehouse, editor. The biology of penguins. Macmillan, London, England.

Williams, A. J. 1980. Aspects of the breeding biology of the gentoo penguin, Pygoscelis papua. Gerfaut 70:283-295.

Williams, T. D. 1995. The penguins. Oxford University Press, Oxford, United Kingdom.

Wilson, R. P., B. Culik, R. Danfeld, and D. Adelung. 1991. People in Antarctica-how much do Adélie penguins Pygoscelis adeliae really care? Polar Biology 11:363-370.

Yorio, P., and P. D. Boersma. 1992. The effects of human disturbance on Magellanic penguin Spheniscus magellanicus behaviour and breeding success. Bird Conservation International 2:161-173.

Yorio, P., P. D. Boersma, E. Frere, P. Gandini, and W. Conway. 1999. Status and conservation of seabirds breeding in Argentina. Bird Conservation International 9:299-314.

Yorio, P., P. D. Boersma, E. Frere, and A. Schiavini. 2001. Tourism and recreation at seabird breeding sites in Patagonia, Argentina: current concerns and future prospects. Bird Conservation International 11:231245.

Yorio, P., and F. Quintana. 1996. Effects of human disturbance on a mixed-species seabird colony in Patagonia. Hornero 14:60-66.

Zar, J. H. 1996. Biostatistical analysis. Third edition. Prentice Hall, Upper Saddle River, New Jersey, USA.

Associate Editor: Brown. 